\title{
ĐÁNH GIÁ KHẢ NĂNG ÚNG DỤNG CỦA ĐO CAO VỆ TINH TRONG VIỆC XÁC ĐỊNH ĐỘ CAO MỰC NƯỚC SÔNG CỦU LONG
}

\author{
ThS. NGUYẼ̃N HÀ PHÚ, KS. VŨ TH! TUYÉT \\ Cục Viễn thám quốc gia
}

\section{Tóm tắt:}

Giám sát sự biến đổi về không gian và thời gian đối với tài nguyên nước trên bề mặt lục địa là vô cùng quan trọng nhằm đáp ứng nhu cầu đòi hỏi của con người phục vụ phát triển kinh tế xã hội và đánh giá sự biến đổi khí hậu toàn cầu đang diễn ra. Tiến hành thực nghiệm trên khu vực sông Cửu Long cho thấy đối với khu vực địa hình bằng phẳng, độ dốc sông không lớn và độ rộng sông trong khoảng từ $0.5 \mathrm{~km}$ đến $1.0 \mathrm{~km}$ thì việc sử dụng các loại dũ liệu đo cao vệ tinh như ENVISAT và Jason-2 cho phép theo dõi biến đổi mực nước sông với trường hợp khả quan nhất có thể đạt đến độ chính xác xấp xỉ $0.2 \mathrm{~m}$, và trong phần lớn trường hợp trung bình từ $0.4 \mathrm{~m}$ đến $0.5 \mathrm{~m}$. Các yếu tố như độ rộng sông, địa hình, sự hiện diện của các bãi bồi giữa dòng chảy, các đối tượng khu dân cư và lớp phủ thực vật tại vị trí giao cắt của vệt quỹ đạo vệ tinh với bề mặt nước là những yếu tố chính ảnh hưởng nhiều đến độ chính xác.

\section{Giới thiệu}

Sông Mekong là một trong những dòng sông lớn nhất trên thế giới với chiều dài $4.220 \mathrm{~km}$ và diện tích lưu vực 795.000 km², đứng thứ 12 nếu xét về chiều dài sông và thứ 10 nếu xét về tổng lưu lượng dòng chảy năm. Khởi nguồn từ cao nguyên Tây Tạng, sông Mekong chảy qua lãnh thổ của 6 quốc gia là Trung Quốc, Myanma, Lào, Thái Lan, Campuchia và Việt Nam. Tại Việt Nam, sông Mekong chia thành hai nhánh chính là sông Tiền và sông Hậu trước khi đổ ra biển Đông qua chín cửa sông, hình thành nên một vùng châu thổ rộng lớn được gọi là đồng bằng sông Cửu Long (ĐBSCL) [1]. Với diện tích tự nhiên trên 4 triệu héc ta, ĐBSCL là trung tâm nông nghiệp lớn nhất cả nước, có tiềm năng to lớn trong phát triển kinh tế xã hội. Tuy nhiên, sự phát triển kinh tế nói chung và nông nghiệp nói riêng ở ĐBSCL phụ thuộc rất lớn vào nguồn nước sông Cửu Long, nhất là trong giai đoạn mùa cạn, khi mà lượng nước của sông Mekong ở thượng lưu giảm xuống. Trong những năm tới, sự phát triển kinh tế xã hội của các quốc gia ven sông Mekong dẫn tới nhu cầu sử dụng nước sông ngày càng gia tăng, tạo nên sức ép ngày càng mạnh mẽ, đòi hỏi cần có các giải pháp tăng cường công tác quản lý, khai thác và bảo vệ tốt tài nguyên nước bằng cách củng cố, bổ sung mạng lưới điều tra quan trắc tài nguyên nước.

Là một quốc gia nằm ở phía hạ lưu sông Mekong, công tác nghiên cứu thủy văn và tài nguyên nước ở nước ta gặp nhiều khó khăn do thiếu các số liệu quan trắc tại thượng nguồn các con sông xuyên biên giới. Công nghệ đo cao vệ tinh với khả năng cung cấp dữ liệu toàn cầu là một giải pháp nhằm khắc phục các khó khăn nói trên. Các nghiên cứu trên thế giới đã cho thấy đo cao vệ tinh có thể được ứng dụng trong việc xác định độ cao mực nước sông cũng như tính toán lưu lượng và trữ lượng nước. Những nỗ lực lớn cũng đang được thực hiện để kết hợp dữ liệu đo cao vệ tinh với dữ liệu quan 
trắc thủy văn thực địa nhằm cải thiện khả năng thành lập bản đồ chu trình nước của các con sông lớn.

Nội dung của bài nghiên cứu này nhằm đánh giá độ chính xác xác định độ cao mực nước trên sông Cửu Long từ đo cao vệ tinh sử dụng các loại dữ liệu phổ biến hiện nay như ENVISAT và Jason-2 trên cơ sở so sánh với dữ liệu độ cao mực nước từ các trạm quan trắc thủy văn trên thực địa thuộc Hệ thống khí tượng thủy văn Nam bộ. Việc thực nghiệm được tiến hành cụ thể đối với sông Tiền, một trong số nhánh sông lớn của sông Cửu Long có độ rộng trung bình từ 0,5 đến xấp xỉ $1.5 \mathrm{~km}$. Phần dưới đây sẽ trình bày về phương pháp, các kết quả đạt được cũng như những đánh giá về độ chính xác xác định độ cao mực nước từ đo cao vệ tinh.

\section{Dữ liệu sử dụng}

\subsection{Dũ liệu đo cao vệ tinh ENVISAT và} Jason-2

Vệ tinh ENVISAT (ENVIronmental SATellite) được phóng lên quỹ đạo vào năm
2002 bởi Cơ quan Vũ trụ Châu Âu ESA với mục đích để nghiên cứu về môi trường và quan trắc bầu khí quyển của Trái đất, đại dương, lục địa và băng. Quỹ đạo của vệ tinh ENVISAT có chu kỳ lặp là 35 ngày với khoảng cách giữa các vệt quỹ đạo tại đường xích đạo xấp xỉ $85 \mathrm{~km}$ tương tự như các vệ tinh trước đó ERS-1/2. Kể từ ngày 22 tháng 10 năm 2010, vệ tinh ENVISAT đã chuyển đến quỹ đạo với chu kỳ lặp là 30 ngày với 431 quỹ đạo/chu kỳ thay vì 35 ngày với 501 quỹ đạo/chu kỳ để kéo dài tuổi thọ của vệ tinh thêm 3 năm nữa. Tuy nhiên, vệ tỉnh này đã bị mất liên lạc ngày 8 tháng 4 năm 2012 và ESA chính thức tuyên bố ngừng nhiệm vụ của ENVISAT vào ngày 9 tháng 5 năm 2012.

Trong nghiên cứu này, dữ liệu ENVISAT được sử dụng là tập dữ liệu ENVISAT RA-2 $18 \mathrm{~Hz}$ có chứa trong dữ liệu GDR (Geophysical Data Records) trong khoảng thời gian từ 2006 đến 2008. Dữ liệu này được cung cấp bởi EOHelp thông qua giao thức FTP tại địa chỉ ftp://diss-nasfp.eo.esa.int/altimetry dataset_v2.1/gdr/.

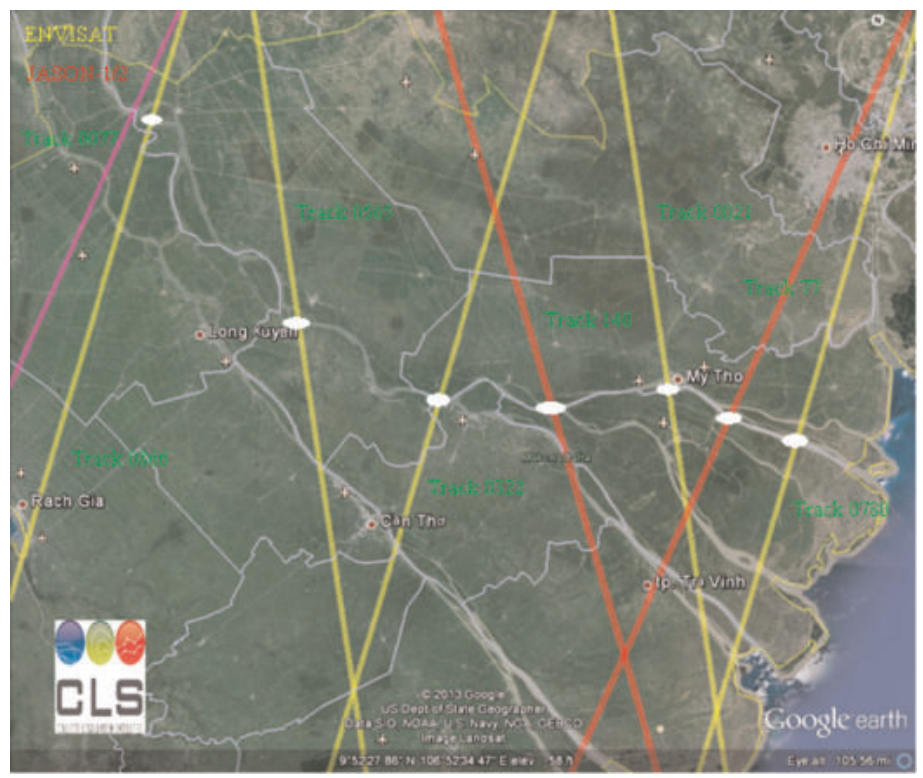

Hình 1: Vị trí các vệt quỹ đạo vệ tinh ENVISAT và Jason-2 
Đối với vệ tinh Jason-2, đây là vệ tinh được phát triển theo chương trình hợp tác giữa CNES, NASA, Eumetsat và NOAA nhằm tiếp quản và kế tục nhiệm vụ của thế hệ các vệ tinh Topex/Poseidon và Jason-1. Vệ tinh này được phóng lên vào năm 2008 theo một quỹ đạo giống như các vệ tinh trước đó với chu kỳ lặp là 10 ngày và khoảng cách giữa các vệt quỹ đạo tại đường xích đạo xấp xỉ $350 \mathrm{~km}$. Nó mang theo một thiết bị đo cao thuộc lớp Poseidon (Poseidon-3) tương tự như Poseidon-2 nhưng với độ nhiễu thiết bị thấp hơn và thuật toán cho phép nhận được các trị đo có chất lượng tốt hơn trên các vùng gần bờ biển, khu vực sông, hồ trong nội địa.

Dữ liệu Jason-2 GDR được sử dụng có chứa các trị đo tần số cao $20 \mathrm{~Hz}$ trong khoảng thời gian từ năm 2009 đến hết năm 2010. Dữ liệu này hiện được cung cấp bởi Trung tâm dữ liệu AVISO/CNES (Archiving, Validation and Interpretation of Satellite Data in Oceanography) thông qua giao thức FTP tại địa chỉ ftp://avisoftp.cnes.fr IAVISO/pub/jason-2/gdr d/.

\section{2. Ảnh vệ tinh}

Ảnh vệ tinh LANDSAT đã được xử lý bức xạ và hình học ở mức 3 (ảnh trực giao) và được kết hợp sử dụng để xác định vị trí chính xác của điểm giao cắt giữa vệt quỹ đạo vệ tinh với bề mặt nước.

\subsection{Dữ liệu thủy văn thực địa}

Hệ thống các trạm thủy văn trên khu vực đồng bằng sông Cửu Long tương đối phát triển và được phân bố trải khắp hầu hết trên tất cả các con sông và những nhánh sông chính. Trong nội dung nghiên cứu này dữ liệu thủy văn được thu nhận ngoài thực địa là các giá trị độ cao mực nước cơ bản trung bình hàng ngày tại một số trạm khí tượng thủy văn trên sông Tiền bao gồm các trạm Tân Châu, Mỹ Thuận và Mỹ Tho. Do các trạm khí tượng thủy văn nói trên có vị trí nằm gần các điểm giao cắt của các vệt quỹ đạo vệ tinh với bề mặt sông nên sự thay đổi mực nước tại đó có thể dùng để đánh giá kết quả chuỗi mực nước theo thời gian từ các trị đo vệ tinh ENVISAT và Jason-2. Dữ liệu thủy văn này được cung cấp bởi Trung tâm Thông tin và Dữ liệu thủy văn và đã được tính chuyển về Hệ độ cao quốc gia.

\section{Xử lý dữ liệu đo cao vệ tinh}

\subsection{Tính độ cao mực nước bằng đo cao vệ tinh}

Dữ liệu đo cao vệ tinh được sử dụng là kiểu dữ liệu tần số cao dọc theo vệt quỹ đạo và được lưu giữ dưới khuôn dạng mã NetCDF do đó yêu cần cần phải có các phần mềm chuyên dụng để đọc và xử lý dữ liệu. Trong nghiên cứu này, chúng tôi sử dụng phần mềm BRAT (Basic Radar Altimetry Tools) là phần mềm mã nguồn mở được phát triển bởi CNES/ESA bao gồm một tập hợp các công cụ được thiết kể để hỗ trợ cộng đồng người sử dụng trong việc xử lý dữ liệu đo cao vệ tinh radar. Phần mềm này có khả năng đọc được hầu hết các loại dữ liệu đo cao vệ tinh phổ biến hiện nay đồng thời cho phép thực hiện xử lý, biên tập, tạo bảng thống kê, hiển thị và kết xuất kết quả. Tất cả các chu kỳ dữ liệu của trị đo cao vệ tinh được nhập vào cùng lúc để tính toán phục vụ cho việc xây dựng chuỗi độ cao mực nước theo thời gian.

Phần mềm BRAT cho phép chiết xuất các thông tin về tọa độ của trị đo cao vệ tinh tần số cao từ các trường dữ liệu độ kinh (Lon) và độ vĩ (Lat) trong các bản ghi dữ liệu ENVISAT GDR RA-2 18hz và Jason-2 GDR 20hz. Chỉ các trị đo được giới hạn khái lược trong phạm vi nghiên cứu mới được xử lý nhằm giảm thời gian và khối lượng tính toán. Tuy nhiên, do phần mềm này đang trong quá trình phát triển và còn có những hạn chế nhất định trong việc biểu diễn và phân tích dữ liệu nên kết quả sau một số bước tính toán sẽ được xuất ra dưới 
dạng ASCll để phục vụ cho các bước tính toán tiếp theo. Kết quả được xuất ra sẽ là tệp dữ liệu tọa độ (Lon, Lat) và độ cao mực nước của các trị đo cao vệ tinh tần số cao.

Đối với nghiên cứu thủy văn lục địa như sông, hồ hay đất ngập nước, độ cao mực nước được xác định bởi chênh cao giữa độ cao quỹ đạo vệ tinh (Alt) với trị đo khoảng cách $R$ và các số hiệu chỉnh khác nhau bao gồm trễ thời gian khi các xung tín hiệu radar đi qua môi trường khí quyển cũng như ảnh hưởng của thủy triều Trái đất. Theo Calmant và các cộng sự (2008) [2], biểu thức tính độ cao mực nước $W S H$ được biểu thị như sau:

$$
W H S=A l t-R+\left[D T C+W T C+I C+T_{S}\right.
$$

Với DTC là số hiệu chỉnh khúc xạ ở tầng đối lưu khô; WTC là số hiệu chỉnh khúc xạ ở tầng đối lưu ướt; IC là số hiệu chỉnh khúc xạ ở tầng điện ly và $T_{S}$ là số hiệu chỉnh do ảnh hưởng thủy triều Trái đất rắn. Trong trường hợp này, các số hiệu chỉnh khúc xạ được sử dụng là các số hiệu chỉnh mô hình tiểu chuẩn trong bản ghi dữ liệu GDR. Các số hiệu chỉnh MWR hay DORIS không được sử dụng do thường xuyên bị mất giá trị. Trị đo khoảng cách $R$ được chúng tôi sử dụng là trị đo được xử lý bằng thuật toán ICE-1 hay "Offset Center of Gravity" đã được chứng minh là phù hợp nhất cho các ứng dụng thủy văn (Frappart cùng các cộng sự, 2006) [3]. Độ cao mực nước được quy chiếu về mặt EGM96.

Khác với thủy văn truyền thống, trong đo cao vệ tinh, vị trí giao cắt giữa vệt quỹ đạo vệ tinh với bề mặt nước sông, hồ không cố định mà dao động trong pham vi $\pm 1 \mathrm{~km}$ theo các chu kỳ và được định nghĩa bằng khái niệm trạm "ảo" (virtual station). Mỗi một trạm "ảo" sẽ được xác định bởi một cửa sổ hình chữ nhật nhằm giới hạn một cách chính xác nhất có thể các trị đo vệ tinh tại vị trí giao cắt của vệt quỹ đạo vệ tinh với bề mặt nước sông, hồ [4]. Vị trí quy ước của nó là kinh độ, vĩ độ trung bình của các trị đo cao vệ tinh trong phạm vi cửa sổ hình chữ nhật đó. Việc xác định chính xác tọa độ địa lý của các trạm "ảo" này được thực hiện trên cơ sở hiển thị tọa độ của các trị đo cao vệ tinh tần số cao trên nền bình đồ ảnh vệ tinh LANDSAT đã được quy chiếu về cùng một hệ tọa độ bằng cách sử dụng các phần mềm đồ họa nhu MicroStation/IrasC, ArcGIS,...Khi đó, các trị đo cao vệ tinh được giới hạn chính xác trong phạm vi cửa sổ chữ nhật của trạm "ảo" sẽ được tính toán lại và kết xuất kết quả tọa độ và độ cao mực nước ra dưới dạng tệp dữ liệu với định dạng ASCII. Cuối cùng, giá trị độ cao mực nước tại mỗi chu kỳ có thể được tính bằng cách lấy giá trị trung bình (mean). Độ chính xác của độ cao mực nước trung bình này có thể đánh giá bằng công thức tính phương sai được biểu diễn như trong phương trình dưới đây:

$$
\sigma=\sqrt{\frac{\sum_{i=1}^{n}\left(x_{i}-\bar{x}\right)^{2}}{N}}
$$

Trong đó, $\bar{x}$ là độ cao mực nước trung bình; $x_{i}$ là độ cao mực nước của mỗi trị đo tần số cao và $N$ là số trị đo tần số cao nằm trong phạm vi cửa sổ chữ nhật của một trạm "ảo". Đồng thời, trong quá trình tính toán các trị đo tần số cao có sai số vượt quá hạn sai cho phép $2 \sigma$ sẽ được coi như sai số thô và bị loại bỏ. Các giá trị độ cao mực nước trung bình và phương sai sẽ được tính toán lại sao cho đảm bảo thỏa mãn điều kiện ràng buộc trên.

Kết quả tính độ cao mực nước theo các chu kỳ giúp xây dựng chuỗi độ cao mực nước theo thời gian. Ngoài ra, chuỗi biến đổi mực nước theo thời gian cũng có thể được tạo ra trên cơ sở so sánh độ cao mực nước của mỗi chu kỳ lặp với độ cao mực nước của một chu kỳ được chọn làm độ cao tham chiếu. 
3.2. So sánh chuỗi biến đổi mực nước từ trị đo cao vệ tinh với chuỗi biến đổi mực nước từ trị đo thủy văn thực địa

Kết quả tính toán mực nước bằng phương pháp đo cao vệ tinh có thể được kiểm định, đánh giá dựa trên cơ sở so sánh với các trị đo thực địa có độ chính xác cao tại một số trạm thủy văn. Tuy nhiên, việc so sánh giữa trị đo cao vệ tinh và trị đo thực địa tại các trạm thủy văn cũng có những hạn chế nhất định khi mà vị trí của các trạm thủy văn không trùng với vị trí quỹ đạo vệ tinh đo cao cắt qua mặt nước. Do vậy, để đánh giá độ chính xác xác định độ cao mực nước chúng tôi sử dụng phương pháp đánh giá tương đối dựa trên giả thiết rằng biến đổi mực nước giữa các trị đo theo trình tự các chu kỳ của vệ tinh đo cao tương tự với biến đổi mực nước của các trị đo thực địa tại trạm thủy văn lân cận đó như đã mô tả bởi Birkett và cộng sự (1998) [5]. Phương pháp so sánh độ cao tương đối như trên có ưu điểm là loại trừ được ảnh hưởng của các sai số hệ thống không mong muốn như: ảnh hưởng của mặt tham chiếu, ảnh hưởng của gió trên bề mặt nước. Theo đó, các trị đo vệ tinh với tần xuất lấy mẫu là 35 ngày đối với
ENVISAT và 10 ngày đối với Jason-2 được so sánh với trị đo thực địa có thời điểm gần nhất của trạm thủy văn lân cận. Tất cả các trị đo lặp theo các chu kỳ cũng được so sánh với một chu kỳ được chọn làm tham chiếu để xác định chuỗi biến đổi mực nước. Chuỗi biến đổi mực nước từ trị đo cao vệ tinh này được so sánh với chuỗi biến đổi mực nước từ trị đo thủy văn thực địa để tính toán độ lệch giữa hai chuỗi độ cao. Sai số trung phương RMS được tính từ các giá trị độ lệch này được dùng để đánh giá độ chính xác xác định chuỗi biến đổi mực nước theo thời gian.

\section{Kết quả và thảo luận}

Sông Tiền có hướng chảy theo hướng từ phía Tây đổ về phía Đông nên tương đối thuận lợi cho quá trình tính toán với trị đo cao của các vệ tinh có quỹ đạo cực. Các vệ tinh đo cao như ENVISAT và Jason-2 đều có những vị trí giao cắt giữa các vệt quỹ đạo vệ tinh với bề mặt nước. Cụ thể, có 3 vị trí giao cắt giữa vệt quỹ đạo vệ tinh ENVISAT với mặt nước theo hướng đi lên (bao gồm các vệt quỹ đạo 433, 161 và 390) và 2 vị trí giao cắt theo hướng đi xuống (các vệt quỹ đạo 283 và 011) đã được lựa chọn, trong khi

Bảng 1: Thống kê chi tiết các trạm "ảo" và trạm thuỷ văn

\begin{tabular}{|c|c|c|c|c|c|c|c|}
\hline Dừ liệu & $\begin{array}{l}\text { vệt } \\
\text { quỳ } \\
\text { dạo }\end{array}$ & $\begin{array}{c}\text { Phạm vi tọa độ địa } \\
\text { lỳ } \\
\text { (WWGS-84) }\end{array}$ & $\begin{array}{l}\text { Chiều } \\
\text { rộng } \\
\text { cựa sô } \\
(\mathrm{km})\end{array}$ & $\begin{array}{l}\text { Chiều } \\
\text { rộng } \\
\text { sồng } \\
(\mathrm{km}) \\
\end{array}$ & $\begin{array}{l}\text { Trạm } \\
\text { thự } \\
\text { vãn }\end{array}$ & $\begin{array}{l}\text { Khoảng cách } \\
\text { đến trạm } \\
\text { thự vàn } \\
\text { (km) }\end{array}$ & $\begin{array}{l}\text { RMS } \\
\text { (m) }\end{array}$ \\
\hline Envisat & 433 & $\begin{array}{l}105.290,10.826 \\
105.312,10.816\end{array}$ & 1.50 & 0.50 & $\begin{array}{l}\text { Tân } \\
\text { Châu }\end{array}$ & $\begin{array}{c}\mathrm{S} \\
\text { (Thuợng luu) }\end{array}$ & 0.629 \\
\hline Envisat & 283 & $\begin{array}{l}105.600,10.415 \\
105.621,10.406\end{array}$ & 1.00 & 0.40 & $\begin{array}{l}\text { Mỹ } \\
\text { Thuận }\end{array}$ & $\begin{array}{c}39 \\
\text { (Hạ lıu) }\end{array}$ & 0.188 \\
\hline Envisat & 161 & $\begin{array}{l}105.888,10.284 \\
105.908,10.269\end{array}$ & 1.60 & 0.56 & $\begin{array}{l}\text { Mỹ } \\
\text { Thuạn }\end{array}$ & $\begin{array}{c}1 \\
\left(\mathrm{H}_{3} \mathrm{l} \text { luu }\right)\end{array}$ & 0.192 \\
\hline Envisat & 011 & $\begin{array}{l}106.338,10.338 \\
106.360,10.325\end{array}$ & 1.50 & 0.90 & Mỹ Tho & $\begin{array}{c}1 \\
\left.\text { ( } \mathrm{H}_{3} \text { louru }\right)\end{array}$ & 0.500 \\
\hline Envisat & 390 & $\begin{array}{l}106.598,10.257 \\
106.619,10.237\end{array}$ & 2.10 & 1.40 & Mỹ Tho & $\begin{array}{c}30 \\
\text { (Thrợng luru) }\end{array}$ & 0.419 \\
\hline Jason-2 & 140 & $\begin{array}{l}106.117,10.291 \\
106.139,10.275\end{array}$ & 1.70 & 1.00 & Mỹ Tho & $\begin{array}{c}25 \\
\text { (Hạ lıus) }\end{array}$ & 0.248 \\
\hline Jason-2 & 077 & $\begin{array}{l}106.469,10.292 \\
106.485,10.276\end{array}$ & 1.80 & 0.80 & Mỹ Tho & $\begin{array}{c}15 \\
\text { (Thương luru) }\end{array}$ & 0.243 \\
\hline
\end{tabular}


đó, số lượng vị trí giao cắt của vệ tinh Jason-2 là 2 vị trí tương ứng với 1 vệt quỹ đạo đi lên (077) và 1 vệt quỹ đạo đi xuống (140).

Trước hết, một vấn đề cần phải được quan tâm là đánh giá về độ chính xác của các trị đo thô tần số cao. Bảng 1 cho thấy các số liệu thống kê chi tiết về các trạm "ảo" trong đo cao vệ tinh. Sai số trung phương RMS của các trị đo cao vệ tinh thô tần số cao trong phạ vi cửa sổ hình chữ nhật có giá trị trong khoảng từ $0.188 \mathrm{~m}$ đến $0.629 \mathrm{~m}$. Đối với các trị đo ENVISAT, mặc dù có độ rộng trung bình tương đương nhau tại các điểm giao cắt của vệt quỹ đạo vệ tinh như 433, 283, 161 và 011 nhưng chất lượng của các trị đo này thể hiện qua sai số RMS lại khác biệt nhau nhiều. Sự khác biệt này phần lớn do ảnh hưởng của yếu tố hình thái bề mặt tại những vị trí giao cắt (Hình 2). Những vị trí giao cắt có sai số lớn là do chịu ảnh hưởng tổng hợp bởi các yếu tố nhu: dòng sông bị phân nhánh, sự xuất hiện của các bãi bồi giữa dòng chảy hay khu dân cư, các công trình xây dựng và lớp phủ thực vật trên mặt đất ở xung quanh trong phạm vi chỉ $5 \mathrm{~km}$. Thực tế, các vệ tinh đo cao được thiết kế để nghiên cứu đại dương với diện tích chiếu xạ vài $\mathrm{km}$ nên những yếu tố trên đã tác động và gây ra nhiễu đến tín hiệu phản hồi dẫn đến kết quả tính toán thiếu chính xác.

So sánh sai số của vị trí giao cắt của vệt quỹ đạo vệ tinh ENVISAT (390) với các vị trí giao cắt của vệt quỹ đạo vệ tinh Jason-2 $(140,077)$ ta thấy mặc dù độ rộng sông tương đương nhau (thậm chí độ rộng sông tại vị trí giao cắt của vệt quỹ đạo vệ tinh ENVISAT có phần nhỉnh hơn) và hình thái bề mặt phức tạp như nhau nhưng kết quả tính toán của các trị đo Jason-2 tốt và ổn định hơn nhiều so với kết quả tính toán của

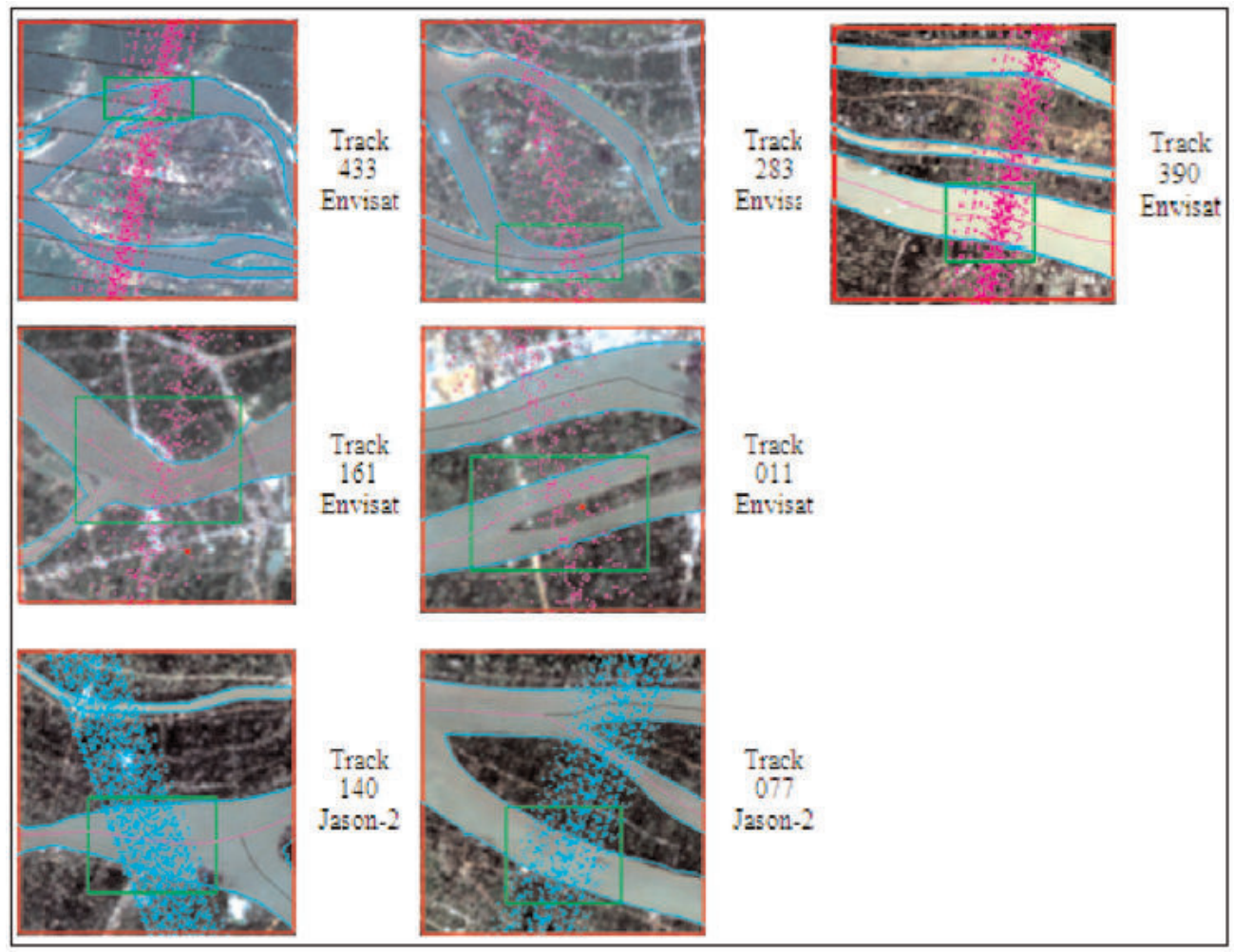

Hình 2: Các vị trí giao cắt của vệt quỹ đạo vệ tinh với mặt sông 
các trị đo ENVISAT. Điều này có thể do khoảng cách lấy mẫu dọc theo quỹ đạo của vệ tinh Jason-2 (290 m) nhỏ hơn của vệ tinh ENVISAT (400 m).

Trong mỗi chu kỳ đo, giá trị độ cao mực nước được tính bằng giá trị trung bình từ tất cả các trị đo tần số cao có trong cửa sổ chữ nhật của trạm "ảo". Việc lọc các trị đo kém có thể thực hiện bằng cách áp dụng điều kiện tiêu chuẩn. Kết quả tính phương sai cho thấy rằng với mực nước cao, phần lớn giá trị phương sai có thể nhỏ hơn $0.25 \mathrm{~m}$, trong khi, với mực nước thấp, giá trị phương sai nằm trong khoảng từ $0.25 \mathrm{~m}$ đến $0.50 \mathrm{~m}$, và đặc biệt khi mực nước xuống thấp hơn nữa độ rộng của sông tại các điểm giao cắt bị thu nhỏ lại thì giá trị phương sai tăng lên nhanh chóng. Đó cũng

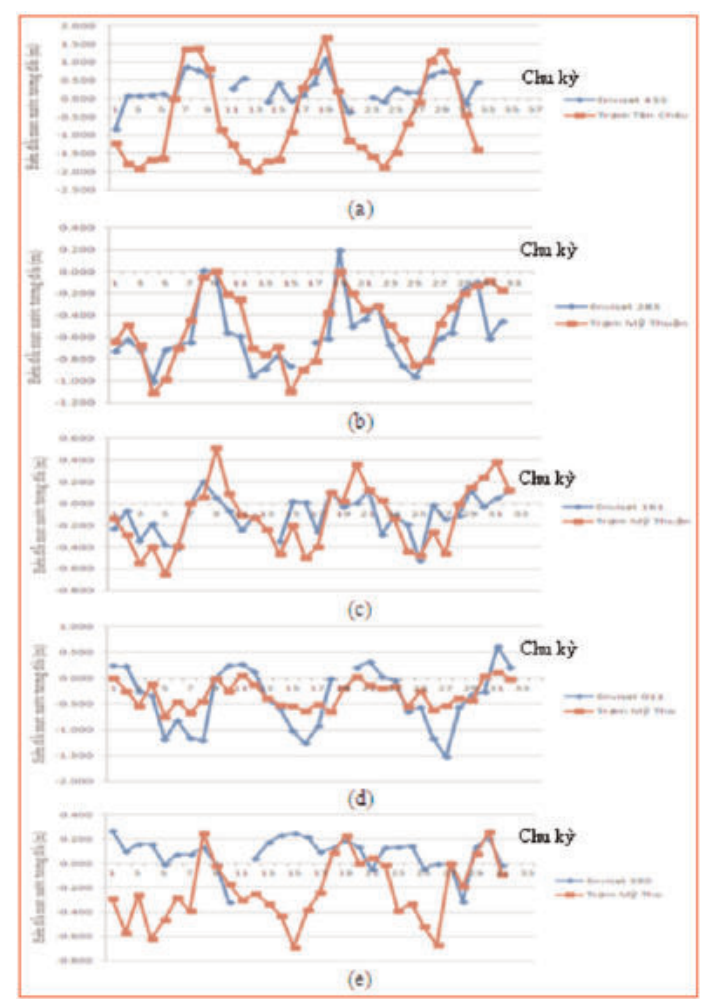

Hình 3: So sánh chuỗi biến đổi mực nước từ đo cao vệ tinh ENVISAT với chuỗi biến đổi mực nước từ trị đo thực địa của trạm thuỷ văn có thể là nguyên nhân khi mà trên khu vực thực nghiệm sông Cửu Long, dữ liệu ENVISAT thường bị thiếu một vài chu kỳ đo ứng với những thời điểm mực nước sông đang xuống rất thấp.

Hình 3 và Hình 4 biểu diễn bằng đồ thị kết quả so sánh chuỗi biến đổi mực nước tính từ dữ liệu đo cao vệ tinh với chuỗi biến đổi mực nước thu được từ các trị đo thực địa tại các trạm thủy văn lân cận tương ứng với 2 loại dữ liệu là ENVISAT và Jason-2. Kết quả đánh giá độ chênh lệch giữa hai chuỗi biến đổi mực nước này được thể hiện như trong Bảng 2 dưới đây. Chúng ta có thể kết luận rằng các chuỗi biến đổi mực nước từ đo cao vệ tinh cho kết quả tốt nhất là tại các điểm giao cắt với vệt quỹ đạo 283 và 161 đối với dữ liệu ENVISAT và điểm giao cắt với vệt quỹ đạo 077 đối với dữ liệu Jason-2. Sai số trung phương độ lệch giữa hai chuỗi biến đổi mực nước của chúng xấp xỉ khoảng $0.22 \mathrm{~m}$. Đồng thời cũng có thể rút ra rằng, trên cùng một dòng chảy với điều kiện địa hình không phức tạp, độ dốc dòng chảy không lớn thì có thể sử dụng dữ liệu thực địa của các trạm thủy văn trong phạm vi khoảng $40 \mathrm{~km}$ để so sánh và đánh giá.

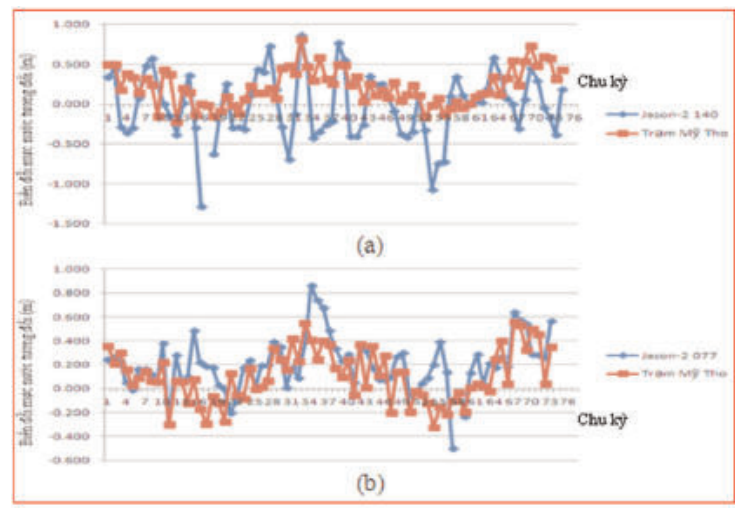

Hình 4: So sánh chuỗi biến đổi mực nước từ đo cao vệ tinh Jason-2 với chuỗi biến đổi mực nước tù trị đo thực địa của trạm thuỷ văn

Có sự tương đồng về hình thái bề mặt khi cùng chịu ảnh hưởng của các yếu tố 
như dòng chảy bị phân dòng hay sự có mặt của khu vực dân cư và lớp phủ bề mặt, nhưng điểm giao cắt của vệt quỹ đạo vệ tinh ENVISAT 011 lại cho kết quả chuỗi biến đổi mực nước tốt hơn so với điểm giao cắt của vệt quỹ đạo vệ tinh ENVISAT 433. Sai số RMS của chúng tương ứng là $0.384 \mathrm{~m}$ so với $1.237 \mathrm{~m}$. Điều này chủ yếu là do độ rộng sông tại điểm giao cắt của vệt quỹ đạo vệ tinh ENVISAT 011 có kích thước lớn hơn và vị trí của trạm thủy văn Mỹ Tho mà các trị đo thực địa của nó được sử dụng để xây dựng chuỗi biến đổi mực nước khi so sánh với chuỗi biến đổi mực nước của điểm giao cắt của quỹ đạo vệ tinh ENVISAT 011 chỉ cách $1.0 \mathrm{~km}$ về phía hạ lưu. Trong khi đó, điểm giao cắt của vệt quỹ đạo vệ tinh ENVISAT 433 có độ rộng tương đối hẹp, khi mực nước giảm các trị đo thường thiếu chính xác và số lượng chu kì đo bị thiếu cũng nhiều hơn. Nếu áp dụng các điều kiện để lọc bỏ các trị sai số thô lớn, thì sai số trung phương RMS của nó ước tính là $0.499 \mathrm{~m}$ khi chỉ tính riêng cho các trị đo tương ứng với mực nước cao.

Bảng 2: Tổng hợp kết quả đánh giá độ chính xác xác định chuỗi biến đổi mực nước trên khu vực sông Cửu Long

\begin{tabular}{|cccc|}
\hline Dữ liệu & Quỹ đạo & Trạm thùy vãn & R.IS (m) \\
\hline ENVISAT & 433 & Tân Châu & $\begin{array}{c}1.237 \\
(0.499)\end{array}$ \\
ENVISAT & 283 & Mỹ Thuận & 0.206 \\
ENVISAT & 161 & Mỹ Thuận & 0.222 \\
ENVISAT & 011 & Mỹ Tho & 0.384 \\
ENVISAT & 390 & Mỹ Tho & 0.437 \\
Jason-2 & 140 & Mỹ Tho & 0.464 \\
Jason-2 & 077 & Mỹ Tho & 0.218 \\
\hline
\end{tabular}

So với các điểm giao cắt khác, vị trí của điểm giao cắt giữa vệt quỹ đạo vệ tinh ENVISAT 390 với mặt nước nằm ở hạ lưu phía cuối dòng chảy, chỉ cách cửa biển nơi con sông đổ nước vào biển Đông khoảng $18 \mathrm{~km}$. Kết quả biểu diễn trên đồ thị cho thấy chuỗi biến đổi mực nước tại điểm giao cắt này chịu ảnh hưởng của chế độ thủy triều biển gây ra hiện tượng biến đổi mực nước xác định từ đo cao vệ tinh có xu hướng cao hơn so với biến đổi mực nước được tính trung bình hàng ngày xác định từ các trị đo thực địa của trạm thủy văn Mỹ Tho trong những khoảng thời gian khi mực nước sông xuống thấp. Trong trường hợp như vậy, dù độ rộng sông của điểm giao cắt này là lớn nhất so với các điểm giao cắt khác nhưng sai số RMS của nó chỉ đạt mức $0.437 \mathrm{~m}$.

Đối với dữ liệu đo cao vệ tinh Jason-2, trong khi kết quả của chuỗi biến đổi mực nước tại điểm giao cắt của vệt quỹ đạo vệ tinh 077 rất khả quan thì kết quả của chuối biến đổi mực nước tại điểm giao cắt của vệt quỹ đạo vệ tinh 140 lại kém hơn so với kì vọng với sai số RMS chỉ bằng $0.464 \mathrm{~m}$ mặc dù nếu xét về sự ảnh hưởng của các yếu tố hình thái bề mặt thì điểm giao cắt của vệt quỹ đạo vệ tinh 140 lại ít chịu ảnh hưởng hơn. Nguyên nhân chỉ có thể giải thích rằng vị trí điểm giao cắt của vệt quỹ đạo vệ tinh 140 nằm ngay ở nơi mà trước đó các nhánh sông hội tụ lại và ngay sau đó lại phân nhánh thành những dòng chảy khác nhau nên chế độ nước tại vị trí điểm giao cắt của vệt quỹ đạo vệ tinh 140 có sự khác biệt so với chế độ nước trên dòng chảy nhánh nơi có vị trí trạm thủy văn Mỹ Tho.

Phân tích kết quả thực nghiệm cũng đã cho thấy có độ lệch về giá trị độ cao mực nước từ đo cao vệ tinh so với độ cao mực nước từ trị đo thủy văn thực địa. Độ lệch 
này chủ yếu là do sự khác biệt về hệ quy chiếu độ cao giữa hai tập dữ liệu. Nó có thể được coi như là một là một hằng số và được sử dụng để hiệu chỉnh giá trị độ cao mực nước từ đo cao vệ tinh.

\section{Kết luận}

Giám sát sự biến đổi về không gian và thời gian đối với tài nguyên nước trên bề mặt lục địa là vô cùng quan trọng nhằm đáp ứng nhu cầu đòi hỏi của con người phục vụ phát triển kinh tế xã hội và đánh giá sự biến đổi khí hậu toàn cầu đang diễn ra. Tiến hành thực nghiệm trên khu vực sông Cửu Long cho thấy đối với khu vực địa hình bằng phẳng, độ dốc sông không lớn và độ rộng sông trong khoảng từ $0.5 \mathrm{~km}$ đến $1.0 \mathrm{~km}$ thì việc sử dụng các loại dữ liệu đo cao vệ tinh như ENVISAT và Jason-2 cho phép theo dõi biến đổi mực nước sông với trường hợp khả quan nhất có thể đạt đến độ chính xác xấp xỉ $0.2 \mathrm{~m}$, trung bình từ $0.4 \mathrm{~m}$ đến $0.5 \mathrm{~m}$ và trường hợp xấu nhất là $1.2 \mathrm{~m}$. Các yếu tố như độ rộng sông, địa hình, sự hiện diện của các bãi bồi giữa dòng chảy, các đối tượng khu dân cư và lớp phủ thực vật tại vị trí giao cắt của quỹ đạo vệ tinh với bề mặt nước ảnh hưởng nhiều đến độ chính xác. Với điều kiện địa hình phức tạp, độ rộng sông không lớn, dữ liệu ENVISAT có thể cho độ chính xác kém, thiếu tin cậy với nhiều trị đo dưới mức nhiễu và bị loại bỏ. Vì vậy, để đảm bảo độ tin cậy, các trị đo mực nước từ đo cao vệ tinh cần được theo dõi một cách liên tục nhằm loại trừ các trị đo thiếu chính xác không đáp ứng được các điều kiện tiêu chuẩn. $O$

\section{Tài liệu tham khảo}

[1]. Lê Anh Tuấn 2004, Đặc điểm chế độ khí tượng - thủy văn vùng đồng bằng sông Cửu Long, Giáo trình giảng dạy, Trường Đại học Cần Thơ.

[2]. Calmant, S., Seyler, F. Crétaux, J.F. 2008, Monitoring continental surface water by satellite altimetry, Surv Geophysics, Vo. 29 , pp. $247-269$.

[3]. Frappart, F., Calmant, S., Cauhopé, M., Seyler, F., Cazenave, A. 2006, Preliminary Results of ENVISAT RA-2 Derived Water Levels Validation over the Amazon Basin, Remote Sensing of Environment, Vol. 100, no. 2, pp. $252-264$.

[4]. Rosmorduc, V., Benveniste, J., Bronner, E., Dinardo, S., Lauret, O., Maheu, C., Milagro, M., Picot, N. 2011, Radar Altimetry Tutorial, ESA \& CNES, pp. 307.

[5]. Birkett, C.M. 1998, Contribution of the TOPEX NASA radar altimeter to the global monitoring of large rivers and wetlands, Water Resource Research, Vol. 34, no. 5 , pp. $1223-1239.0$

\section{Summary}

\section{Assess the applicability of satellite altimetry in determining the water level in the Mekong River}

\section{MSc. Nguyen Ha Phu, Eng. Vu Thi Tuyet, National Remote Sensing Department}

River water level variation monitoring on surface water resource management is crucial for socio-economical development and global warming. This research was performed in Mekong Delta Basin to access on the quality of satellite-derived water level using ENVISAT and Jason-2 datasets. The results show that water level accuracy is variable from $0.2 \mathrm{~m}$ in the best cases to $0.5 \mathrm{~m}$ in most cases. These accuracies are affected by some factors including river width, terrain, braided river as well as forest and settelement features around the intersection of the satellite track and water surface. $O$

Ngày nhận bài: 13/02/2015. 